\title{
A Springback Prediction Model for Warm Forming of Aluminum Alloy Sheets Using Tangential Stresses on a Cross-Section of Sheet
}

\author{
Heung-Kyu Kim ${ }^{1}$ and Woo-Jin $\mathrm{Kim}^{2, *}$ \\ 1 Department of Automotive Engineering, Kookmin University, 77 Jeongneung-ro, Seongbuk-gu, \\ Seoul 136-702, Korea; krystal@kookmin.ac.kr \\ 2 Department of Materials Science and Engineering, Hongik University, Mapo-gu, Sangsu-dong 72-1, \\ Seoul 121-791, Korea \\ * Correspondence: kimwj@wow.hongik.ac.kr; Tel.: +82-2-320-1468
}

Received: 22 February 2018; Accepted: 5 April 2018; Published: 10 April 2018

\begin{abstract}
Warm U-draw bending tests were performed on a 5182 aluminum alloy under isothermal and non-isothermal conditions, and the amounts of springback under the corresponding conditions were measured. Finite element method analyses were then conducted to calculate the tangential stress distribution on the cross-section of the sheet during the warm forming process. It was found that the experimentally measured springback values were proportionally related to the differences in the amounts of tangential stresses at the top and bottom layers of the sheet section. A functional model that can account for the correlation between the amount of springback and the difference in tangential stresses at the top and bottom layers of the sheet section was derived based on an Euler beam and a nonlinear flow stress model with temperature and strain rate dependencies. The developed model, which can predict springback behavior using only results of forming analyses of warm formed aluminum alloy sheets, is anticipated to provide for advancements in the understanding of springback behavior at warm temperatures and improve the efficiency of design and analysis processes used to fabricate parts with complicated shapes by saving considerable time and costs for the analysis of springback.
\end{abstract}

Keywords: aluminum alloys; springback; warm forming; tangential stress

\section{Introduction}

The application of aluminum alloys to automobile structural and body parts has been attractive from the viewpoint of improving vehicle fuel efficiency [1]. Aluminum alloys, however, have low formability compared to steels at room temperatures and large springback at room temperature, which limit the widespread use of aluminum alloys in the automotive industry and thus have seen limited use for the production of parts with high shape complexity. For many years, hot forming and warm forming methods have been studied and applied to improve the formability of aluminum alloys. Ismail and Mohamed [2] reviewed various forming techniques applicable to aluminum alloy sheets. Naka et al. [3] experimentally investigated the effects of temperature and forming speed on the forming limit of 5083 aluminum alloy sheets with fine grains. Kim et al. [4] showed that aluminum alloy tubes could be produced by hot-gas forming and that failure during forming could be predicted by a fracture criteria based on the Zener-Hollomon parameter. Rashid et al. [5] proposed the quick plastic forming, which is a method of stretching magnesium-containing aluminum alloy sheets into intricate shapes as required for automotive body panels. Hot forming has an advantage when fabricating aluminum alloys into complicated shapes with sharp corners and small radii. Unlike hot forming, warm forming does not provide high ductility to the materials because its working temperature range $\left(200\right.$ to $\left.400{ }^{\circ} \mathrm{C}\right)$ 
is lower than that for hot forming $\left(400\right.$ to $\left.500^{\circ} \mathrm{C}\right)$. However, warm forming offers a higher formability than cold forming. Another advantage of warm forming over cold forming is that flow-stress level of aluminum alloys during forming is lower at warm temperatures, leading to decrease in springback. Laurent et al. [6] investigated the mechanical behavior of AA5754-O alloys in warm forming conditions and showed that warm temperature reduces a stress gradient in the cup walls leading to a reduction in springback. Kim et al. [7] used the finite element analysis and design of experiments together to determine the temperature conditions of the warm forming process that can improve the formability of the aluminum sheet. In general, more material and process parameters are involved in a warm forming process than in a cold forming process because the strength of the material depends on temperature and strain rate, and the coefficient of friction between the die and workpiece varies with temperature. Therefore, in order to predict the deformation behavior and forming limit during warm forming, it is necessary to consider these temperature-dependent parameters when performing forming analyses. There are many papers on aluminum alloys regarding this issue. Takuda et al. [8] performed numerical simulations of warm deep drawing of aluminum alloy sheets and analyzed the forming limit behavior at elevated temperatures. Li and Ghosh [9] investigated the uniaxial tensile deformation behaviors of aluminum sheet alloys in the warm forming temperature range and found that uniaxial tensile elongation increased with increasing temperature and decreased with increasing strain rate. Abedrabbo et al. [10] developed a temperature-dependent anisotropic material model to be used in the finite element analysis for 3003 aluminum alloy sheets. Toros et al. [11] reviewed recent developments in warm forming of aluminum-magnesium alloys such as the effects of temperature and strain rate on formability. However, research on springback in aluminum alloys at warm temperatures is relatively lacking in both experimental and theoretical aspects. Moon et al. [12] investigated the effects of tool temperature on the springback of a 1015 aluminum alloy. Keum and Han [13] conducted draw bending tests on 1050 and 5052 aluminum alloy sheets to measure springback at various forming temperatures and showed that springback decreased, especially at forming temperatures above $150{ }^{\circ} \mathrm{C}$. Yanagimoto and Oyamada [14] conducted a quasi-isothermal forming experiment using the forming dies with a built-in heater aimed at springback-free warm forming of 6016 aluminum alloy sheets. Kim and Koç [15] investigated the effect of temperature gradients on springback in warm forming of 5754 aluminum alloy sheets using a thermo-mechanically coupled finite element analysis and qualitatively explained the springback behavior based on the stress distribution on the sheet cross-section after forming.

The sheet metal forming process is usually divided into two steps. First, in the forming step, a sheet blank is plastically deformed to a desired shape using a press die. In that type of forming process, the sheet material is subjected to stretching and bending deformation, which results in a significantly non-uniform stress distribution on the sheet cross-section. In the unloading step after completion of forming, all load constraints are removed, and elastic recovery is generated so that the bending moment generated in the forming step becomes zero. The forming process and resulting springback behavior are generally predicted using numerical methods such as FEM (finite element method) due to the nonlinearity of the product shape and material properties. In that case, if the forming analysis is performed using implicit finite element code, it may take a long time to obtain a converged solution due to the severe nonlinearity of the forming process, or a converged solution may not be obtained if convergence is not achieved. For that reason, explicit finite element codes free of convergence problems have been widely applied in forming analyses, even though the accuracies of the results are lower compared to cases using implicit codes. Makinouchi et al. [16] investigated the state of explicit sheet metal forming finite element codes used in industries in Europe, Japan and the United States. Narasimhan and Lovell [17] outlined a coupled explicit-to-implicit finite element method for predicting springback deformations in sheet metal forming processes. However, the use of implicit finite element codes is still preferred for most warm forming analyses because implicit finite element codes are more reliable than explicit codes in solving thermo-mechanically coupled problems such as warm forming. On the other hand, implicit codes have been preferentially used 
for springback analysis. This is because the stress distribution of the sheet cross-section should be calculated accurately to reliably predict the springback behavior of the sheet. For these reasons, it is desirable to use implicit codes for both forming and springback analyses of warm forming. However, this requires a significant amount of computational time and cost. If springback behavior in warm forming can be more easily predicted, the sheet metal forming processes and die design for achieving the desired shape of the products by warm forming can be conducted more efficiently.

In this study, we propose a functional model that can easily estimate the springback behavior of a warm-formed aluminum alloy part using only the results of the forming analysis. U draw bending tests were experimentally carried out under elevated temperature conditions, and springback behavior was examined. We found a correlation between the stress data predicted by the forming analysis and the measured springbacks. Inspired by the observed correlation, we derived a functional model that can predict springback in warm $U$ draw bending. The proposed functional model is advantageous in use because total analysis time and cost can be saved by omitting the springback analysis after warm forming.

\section{Experimental Procedures}

\subsection{Material}

The material used in the U draw bending tests was a commercial 5182 alloy sheet with a thickness of $1.1 \mathrm{~mm}$ that was supplied by the Novelis Aluminum Company (Yeongju, Gyeongsangbuk-do, Korea). The microstructure was composed of equiaxial grains $(8.2 \mu \mathrm{m})$ with a high fraction of high angle grain boundaries (0.80) [18], indicating that the material had been fully recrystallized and has fine grains.

\subsection{Uniaxial Tensile Tests}

The tensile properties of 5182 alloy have been examined over wide ranges of strain rates $\left(5 \times 10^{-4}\right.$ to $\left.1 \times 10^{-1} \mathrm{~s}^{-1}\right)$ and temperatures $\left(150-450^{\circ} \mathrm{C}\right)$ in previous work [18]. In this work, additional tensile tests were conducted at lower temperatures of 25 and $100{ }^{\circ} \mathrm{C}$ at various strain rates. A tensile test was conducted once at each condition. Figure 1 shows the true stress-true strain curves of the 5182 alloy obtained from the tensile tests performed at various temperatures and strain rates. As temperature increases and strain rate decreases, work hardening rate and flow stress tend to decrease.

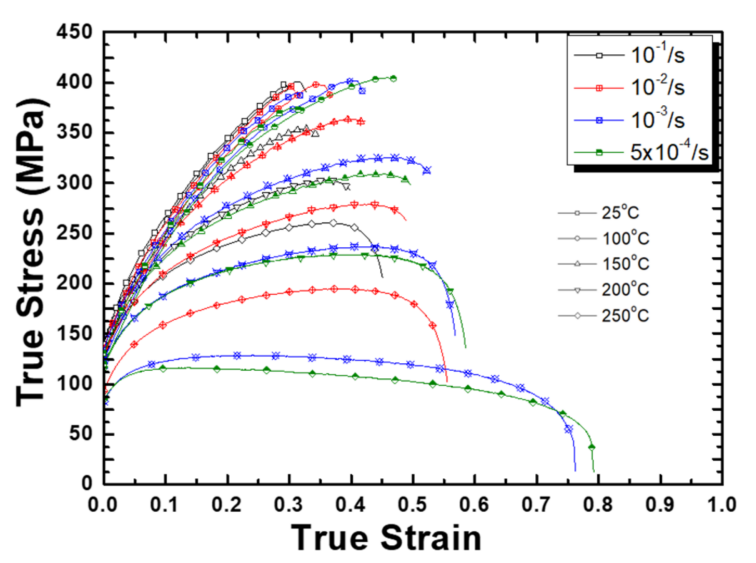

(a)

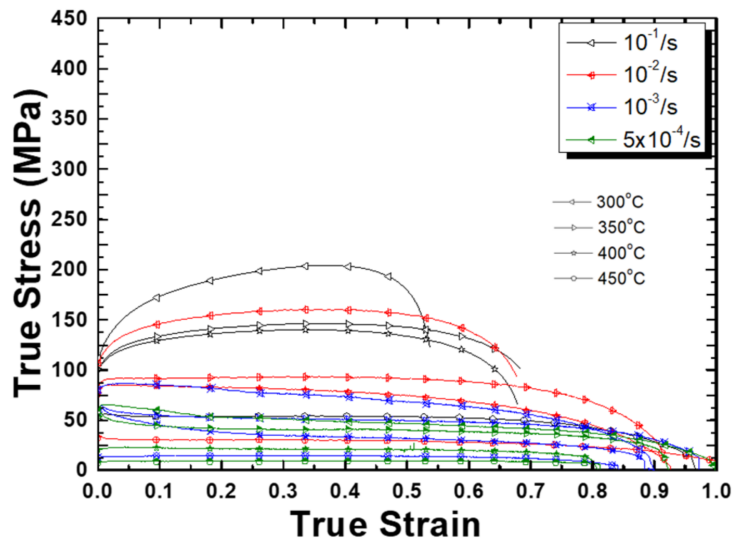

(b)

Figure 1. The true stress-true strain curves of the 5182 alloy obtained from the tensile tests performed in the temperature range (a) between 25 and $250{ }^{\circ} \mathrm{C}$ and (b) between 300 and $450{ }^{\circ} \mathrm{C}$ at different strain rates. 


\subsection{U Draw-Bending Tests}

Figure 2a shows a schematic illustration of the $U$ draw-bending setup. The die and punch shoulder radii were $5 \mathrm{~mm}$, and the clearance between the punch and the die was $1.6 \mathrm{~mm}$. The dimensions of the sheet blank were $350 \mathrm{~mm}$ long, $35 \mathrm{~mm}$ wide, and $1.1 \mathrm{~mm}$ thick. The longitudinal direction of the sheet was parallel to the rolling direction. The loads were applied using an R\&B testing machine (Daejon, Korea), and no lubricant was used for the punch/sheet and die/sheet contact surfaces. A blank holding force (BHF) was supplied by four springs and was set using screw nuts. Drawing was conducted under isothermal and non-isothermal conditions. The sheet was drawn with a constant punch speed of $1 \mathrm{~mm} / \mathrm{s}$ up to a punch stroke of $70 \mathrm{~mm}$ under a constant BHF of $5 \mathrm{kN}$. The tools were heated using heaters inserted into the tools, and their temperatures were controlled to preset values using temperature controllers. Temperatures of 25 (RT: room temperature), 100, 150, 200, 225 and $300{ }^{\circ} \mathrm{C}$ were used. Under non-isothermal drawing conditions, the punch was cooled to $45^{\circ} \mathrm{C}$ by circulating water in it. Punch cooling was adopted based on the experimental observations $[12,19]$ that drawability could be improved when the part of a blank contacting the punch was effectively cooled because localized thinning around the punch corner could be suppressed. The amount of springback after the draw-bending test was evaluated using the $\Delta \theta$, which is indicated in Figure $2 \mathrm{~b}$ where $\theta_{1}$ and $\theta_{2}$ denote the angle between the cup bottom and the sidewall and the angle between the sidewall and the flange, respectively. U-bending test was conducted once at each condition except at $250{ }^{\circ} \mathrm{C}$ under isothermal condition where the test was repeated to check the reproducibility of the test results.

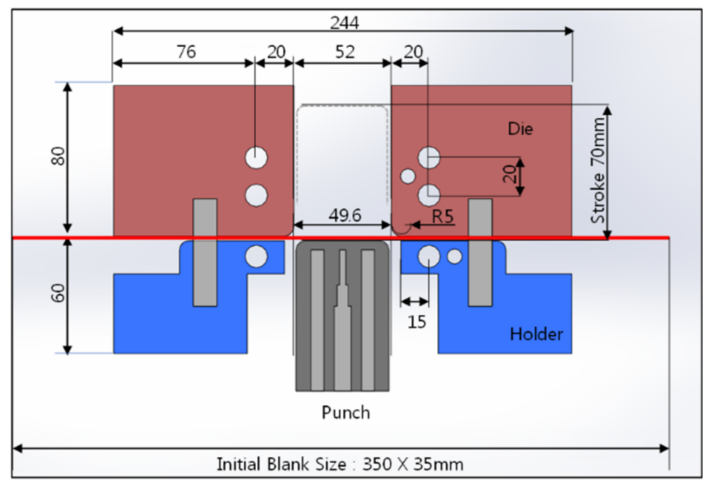

(a)

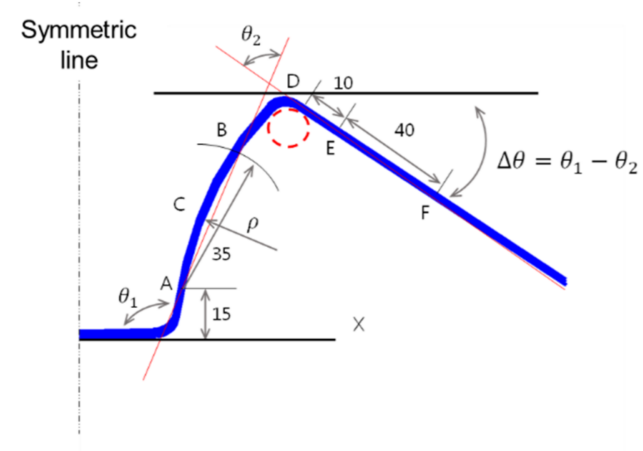

(b)

Figure 2. (a) A schematic illustration of the $U$ draw-bending setup and (b) the amount of springback after the draw-bending test: $\Delta \theta$ (The blue thick line denotes the deformed sheet).

\subsection{Finite Element Method Simulations}

The FEM simulations for the U draw-bending process model were carried out under the same conditions used in the experiments. The uniaxial tensile curves given as a function of temperature, strain rate and strain (Figure 1) were the inputs for the material properties of the blank. In the simulations, in addition to the temperature effect, the effect of punch speed on springback was also studied under both isothermal and non-isothermal conditions, though it was not studied in the experiments. Table 1 shows the detailed simulation conditions. The blank was loaded through the contact forces imposed by the moving punch and resulting interactions with the stationary die and blank holder. The motion of the punch was defined by a prescribed velocity. The coefficient of friction between the workpiece and the tooling elements was assumed to be constant, and Coulomb's friction law with a constant die friction coefficient of 0.1 was used for all of the temperatures [15]. In the FEM simulation for non-isothermal drawing, heat transfer calculations and stress analysis were performed simultaneously using the same mesh. An implicit solution scheme was used for both simulations using a commercially available FE package, Simulfact version 13 (MSC Software Corp., Newport Beach, CA, USA). Four element layers were used through the thickness to properly consider the bending and 
frictional shear effects. For simplicity, the die, punch and blank holder were modeled as rigid surfaces, and the desired temperature conditions were uniformly applied on the tooling surfaces. The heat transfer coefficient at the interface between the tool and material was assumed to be $2800 \mathrm{~W} / \mathrm{m}^{2} \cdot \mathrm{K}$, which gave the best match between the FEM and experimental results.

Table 1. The FEM (finite element method) simulation conditions.

\begin{tabular}{cc}
\hline Material & Al-5182 \\
\hline Density $\left(\mathrm{kg} / \mathrm{m}^{3}\right)$ & 2655 \\
Young's modulus $(\mathrm{GPa})$ & $73.1 \sim 60.3\left(25 \sim 300{ }^{\circ} \mathrm{C}\right)[20]$ \\
Poisson's ratio & 0.25 \\
Specific heat $(\mathrm{J} / \mathrm{kg} \cdot \mathrm{K})$ & $930 \sim 1042\left(50 \sim 350{ }^{\circ} \mathrm{C}\right)$ \\
Thermal conductivity $(\mathrm{W} / \mathrm{m} \cdot \mathrm{K})$ & $113 \sim 128\left(50 \sim 350^{\circ} \mathrm{C}\right)$ \\
Thermal expansion coefficient & $(2.33 \sim 2.63) \times 10^{-5}\left(50 \sim 350{ }^{\circ} \mathrm{C}\right)$ \\
Blank length $(\mathrm{mm})$, Blank width $(\mathrm{mm})$ & 350,35 \\
Blank thickness $(\mathrm{mm})$ & 1.1 \\
Punch speed $(\mathrm{mm} / \mathrm{s})$ & $1,5,10$ \\
Die temperature $\left({ }^{\circ} \mathrm{C}\right)$ & $25,150,200,250,300$ \\
Punch temperature $\left({ }^{\circ} \mathrm{C}\right)$ & $25,150,200,250,300$ \\
Blank holder force $(\mathrm{kN})$ & 2800 \\
Friction coefficient & 5 \\
Contact heat transfer Coefficient $\left(\mathrm{W} / \mathrm{m}^{2} \cdot \mathrm{K}\right)$ & $\mathrm{Coulomb} 0.1$ \\
\hline
\end{tabular}

\section{Results}

Figure 3 shows the flow stresses of the 5182 alloy as measured from their true stress-true strain curves at two plastic strains of 0.1 and 0.2 as a function of temperature. The flow-stress comparison as a function of temperature was made at strains below 0.2 because at strains above 0.2 , fracture occurred at RT. Flow stress decreased with increasing temperature. Flow stress level depended on strain rate. For a given temperature, flow stress increased with increasing strain rate. As temperature increased, the sensitivity of the flow stress to the strain rate increased. Figure 3 also shows that flow stress depended on strain, at temperatures below $300{ }^{\circ} \mathrm{C}$ and at high strain rates. In general, plastic flow stresses of metallic alloys, including aluminum alloys, at constant temperatures can be expressed by [21]

$$
\sigma=K \varepsilon^{N} \dot{\varepsilon}^{m},
$$

where $\sigma$ is the flow stress, $K$ is a material constant, $\varepsilon$ is the strain, $N$ is the strain hardening exponent, $\dot{\varepsilon}$ is the strain rate, and $m$ is the strain rate sensitivity exponent.

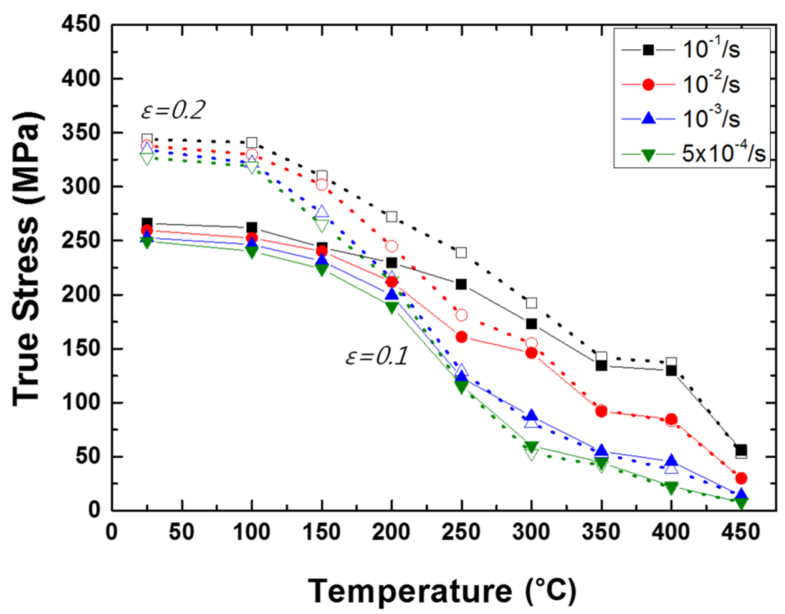

Figure 3. The flow stresses of the 5182 alloy measured from their true stress-true strain curves at plastic strains of 0.1 and 0.2 as a function of temperature. 
At a given strain, the strain rate, $\dot{\varepsilon}$, can be determined using a relationship of the following form at elevated temperatures [22]

$$
\dot{\varepsilon}=\frac{A}{d^{p}} D \sigma^{n},
$$

where $n$ is the stress exponent $(=1 / m), D$ is the atomic diffusivity $\left(=D_{\mathrm{o}} \exp (-Q / R T)\right.$, where $D_{\mathrm{o}}$ is a pre-exponential factor, $Q$ is the activation energy for diffusion, $R$ is the gas constant, and $T$ is the absolute temperature, $d$ is the grain size, $p$ is the grain size exponent, and $A$ is the material constant. Equation (2) can be rewritten as

$$
\sigma=A^{\prime}\left(\frac{\dot{\varepsilon}}{D}\right) m=f\left(\frac{\dot{\varepsilon}}{D}\right)=f(Z)
$$

where $A^{\prime}=\left(\frac{d^{p}}{A}\right)^{m}, Z$ is the Zener-Holloman parameter $\left(Z=\dot{\varepsilon} \exp \left(\frac{Q}{R T}\right)\right)$, and $D=D_{\mathrm{L}}$ or $D=D_{\text {gb }}$ when lattice diffusion $\left(D_{\mathrm{L}}\right)$ or grain boundary diffusion $\left(D_{\mathrm{gb}}\right)$ dominate the plastic flow, respectively. The effective diffusion coefficient, $D_{\text {eff }}$, can be used when both contributions from $D_{\mathrm{L}}$ and $D_{\mathrm{gb}}$ need to be considered simultaneously, and is defined as [23]

$$
D_{\text {eff }}=D_{\mathrm{L}}+f_{\mathrm{gb}} D_{\mathrm{gb}}
$$

where $f_{\mathrm{gb}}$ is the fraction of atoms associated with grain boundaries $(=\pi \delta / d$, where $\delta$, the width of a grain boundary, is assumed to be $2 b$, where $b$ is the Burger's vector). In this case, Equation (3) can be modified to

$$
\sigma=f\left(\frac{\dot{\varepsilon}}{D_{\text {eff }}}\right)=f\left(Z_{\text {eff }}\right),
$$

where $Z_{\text {eff }}$ is the effective Zener-Holloman parameter obtained by considering the contributions from both lattice and grain boundary diffusion [24]. Considering the above, plastic flow stress of an aluminum alloy at elevated temperatures can be generally expressed by

$$
\sigma=K \varepsilon^{N} f\left(Z_{\text {eff }}\right)=K \varepsilon^{N} f\left(\frac{\dot{\varepsilon}}{D_{\text {eff }}}\right) .
$$

Figure 4 shows a plot of $\ln \sigma$ vs. $\ln Z_{\text {eff }}$ for the 5182 alloy for a temperature range between 25 and $450{ }^{\circ} \mathrm{C}$ at a given strain of 0.1 . The $Z_{\text {eff }}$ values were determined using $Q_{\mathrm{L}}=142 \mathrm{~kJ} / \mathrm{mol}$ and $Q_{\mathrm{gb}}=82 \mathrm{~kJ} / \mathrm{mol}$ [23], where $Q_{\mathrm{L}}$ and $Q_{\mathrm{gb}}$ are the activation energies for $D_{\mathrm{L}}$ and $D_{\mathrm{gb}}$ in pure aluminum, respectively.

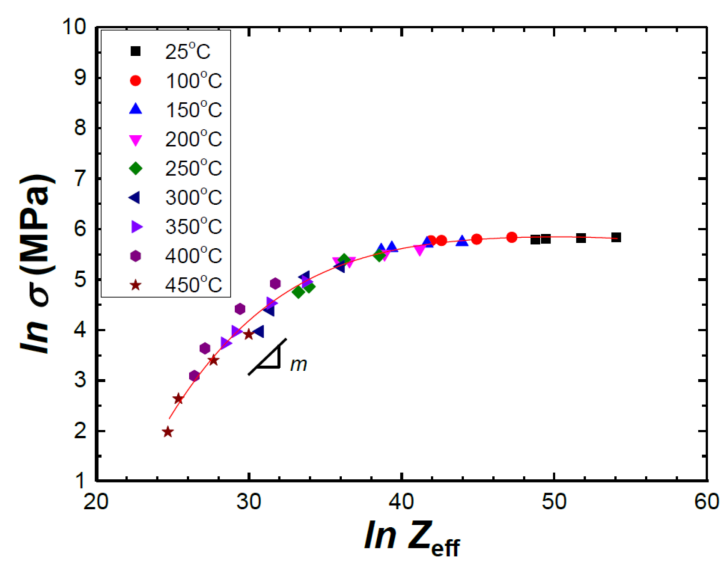

Figure 4. A plot of $\ln \sigma$ vs. $\ln Z_{\text {eff }}$ for the 5182 alloy for a temperature range between 25 and $450{ }^{\circ} \mathrm{C}$ at a given strain of 0.1 . 
As seen, the correlation between $\ln \sigma$ and $\ln Z_{\text {eff }}$ for the 5182 alloy is good, supporting the validity of Equation (6). The correlation plot shows that $\ln \sigma$ is a nonlinear function of $\ln Z_{\text {eff }}$. As the instantaneous slope that represents the $m$ value gradually decreased with increasing $\ln Z_{\text {eff }}$, an expression for the relation between $\ln \sigma$ and $\ln Z_{\text {eff }}$ was obtained by polynomial curve fitting:

$$
\ln \sigma=f_{1}\left(\ln Z_{\text {eff }}\right)=-39.03+3.47 \ln Z_{\text {eff }}-0.10\left(\ln Z_{\text {eff }}\right)^{2}+0.0014\left(\ln Z_{\text {eff }}\right)^{3}+6.9 \times 10^{-6}\left(\ln Z_{\text {eff }}\right)^{4} .
$$

Flow stress can then be expressed by

$$
\sigma=f\left(\ln Z_{\text {eff }}\right)=\exp \left(-39.03+3.47 \ln Z_{\text {eff }}-0.10\left(\ln Z_{\text {eff }}\right)^{2}+0.0014\left(\ln Z_{\text {eff }}\right)^{3}+6.9 \times 10^{-6}\left(\ln Z_{\text {eff }}\right)^{4}\right) .
$$

Figure 5a shows the effects of temperature on the experimental values of $\Delta \theta$ under isothermal conditions. As temperature increased, $\Delta \theta$ decreased and became nearly 0 at $300{ }^{\circ} \mathrm{C}$. The elastic energy stored at a specific strain during plastic deformation in the uniaxial tensile testing is equal to $0.5 \sigma \varepsilon=0.5 \sigma^{2} / E$, indicating that the amount of springback would decrease with decreasing flow stress and increasing $E$. As $E$ of 5xxx aluminum alloy continues to decrease with increasing temperature [20], the $\Delta \theta$ value that decreased with increasing temperature should be attributed to the decrease of flow stress with increasing temperature. Figure $5 b$ shows the effect of temperature on $\Delta \theta$ under non-isothermal conditions, where a trend similar to that noted under isothermal conditions was observed. The amount of springback was relatively large compared to that under isothermal conditions, most likely because the temperature of the material was lower compared to that under the isothermal condition due to the punch cooling under the non-isothermal condition. For both the isothermal and non-isothermal cases, the FEM calculations agreed reasonably well with the experimental results.

To further investigate the reason for the reduction in springback at elevated temperatures, the distribution of tangential stress (i.e., normal stress near the surface on the cross-section of the sheet) of the part before unloading was examined by defining a local coordinate system in the FEM model. The effects of temperature and punch speed on the values and distribution of tangential stresses during isothermal forming are shown in Figures 6 and 7, respectively.

Figure 6a shows each distinct tooling region (i.e., $\mathrm{AB}$ : punch corner, $\mathrm{BC}$ and $\mathrm{CD}$ : sidewall, and $\mathrm{DE}$ : die corner) and Figure $6 \mathrm{~b}-\mathrm{f}$ show the tangential stress values at the top and bottom layers of the blank after completion of $U$ draw-bending (before unloading) at RT and elevated temperatures (150, 200, 250 and $300{ }^{\circ} \mathrm{C}$ ) with a fixed punch speed of $1 \mathrm{~mm} / \mathrm{s}$. At RT, the elements in the punch corner region (the $\mathrm{AB}$ region in Figure 6a) primarily experienced bending, tensile tangential stresses develop in the bottom layer of the sheet, and compressive tangential stresses develop in the top layer. In the die corner region (DE in Figure 6a), the sign of tangential stresses reversed due to the bending changes in the opposite direction. As temperature was increased, the magnitude of tangential stresses throughout the tooling region decreased because the higher temperatures led to lower flow stress and, therefore, decreasing bending moments. The magnitudes of the tangential stresses, however, decreased more rapidly in the $\mathrm{BC}$ region (where both bending and unbending were expected to occur) compared to the other regions. The sign of the tangential stress of the top and bottom layers eventually reversed at temperatures above $250{ }^{\circ} \mathrm{C}$; the stress state changed from tension to compression at the bottom layer and compression to tension at the top layer of the blank. This could occur when the magnitude of the bending moment in the $\mathrm{BC}$ region decreased faster than the magnitude of the unbending moment as temperature increased. 


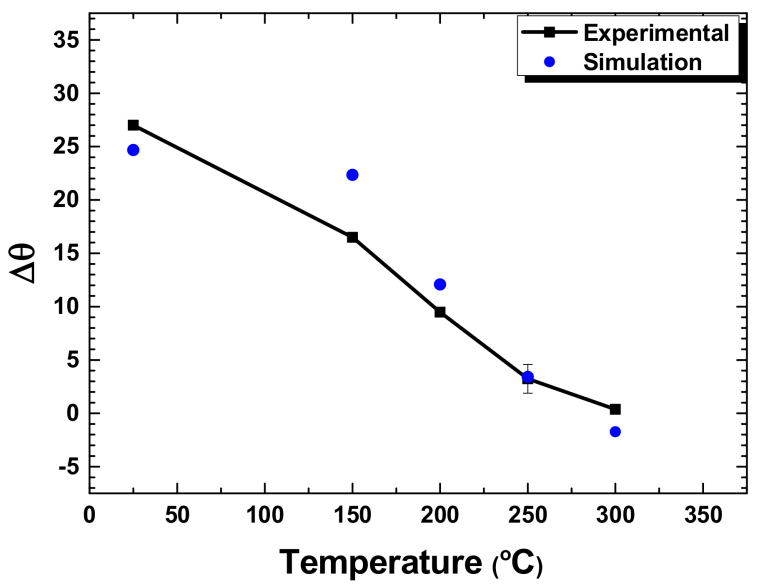

(a)

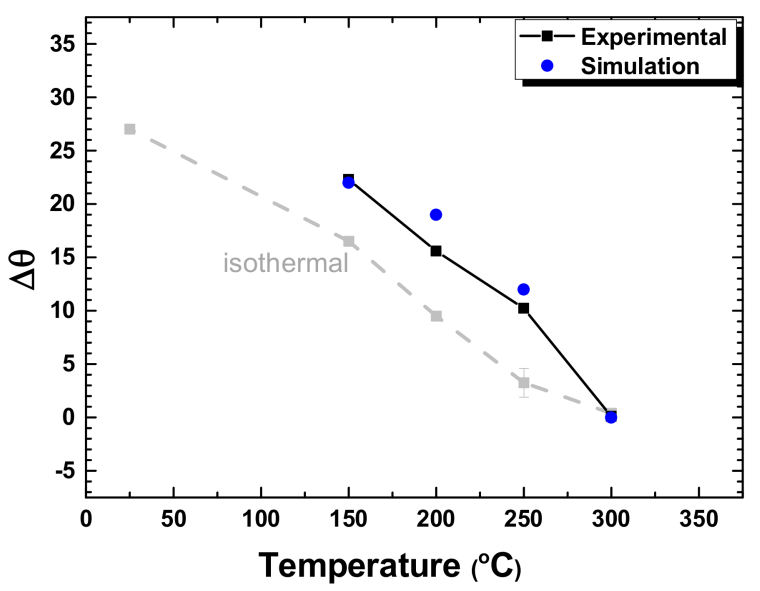

(b)

Figure 5. The effects of temperature on the experimental values of $\Delta \theta$ under (a) isothermal and (b) non-isothermal conditions.

(a)
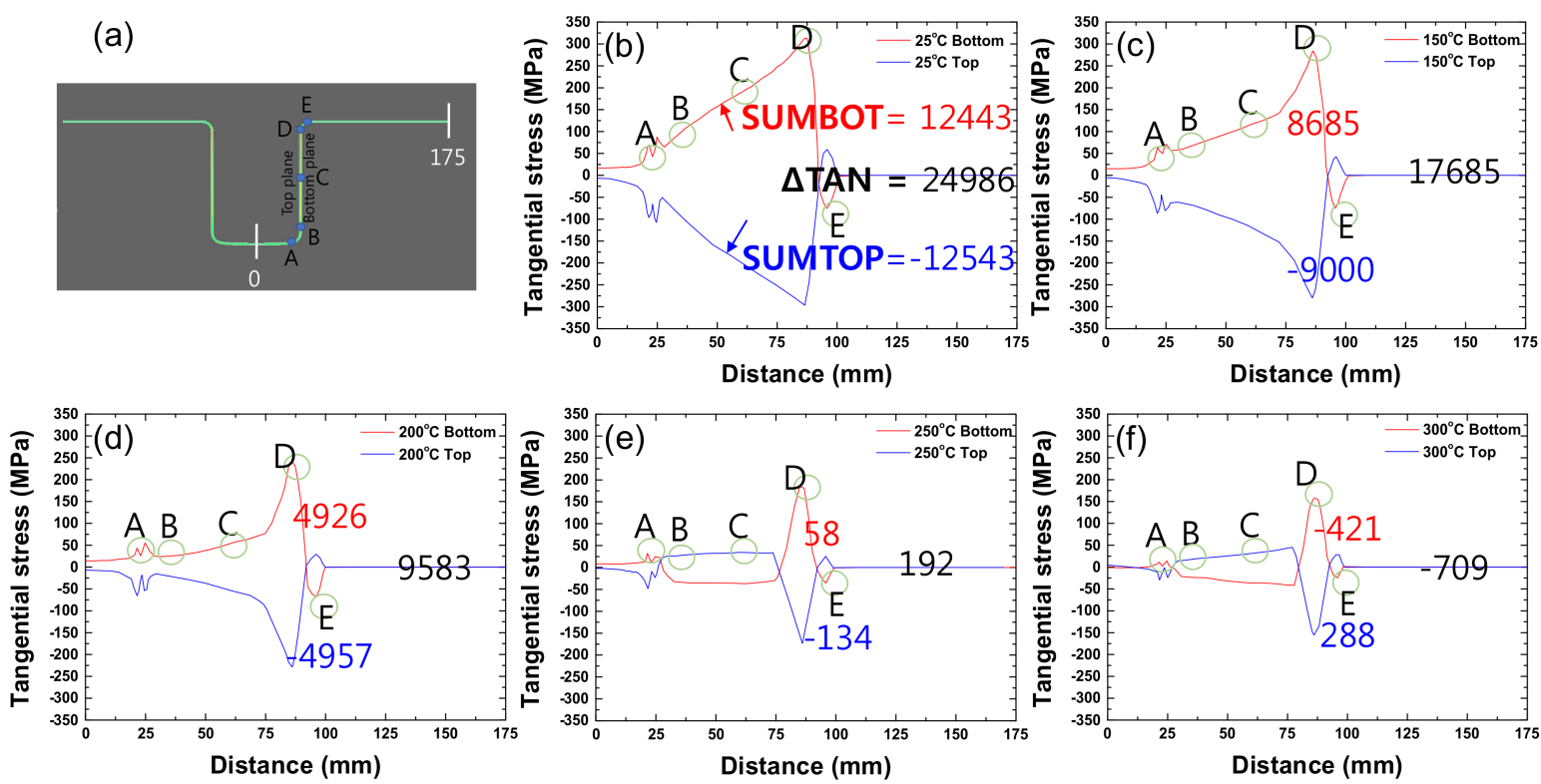

Figure 6. The tangential stress values in (a) each distinct tooling region at the top and bottom layers of the blank (under isothermal condition) at (b) 25, (c) 150, (d) 200, (e) 250 and (f) $300{ }^{\circ} \mathrm{C}$. For all cases, the punch speed was $1 \mathrm{~mm} / \mathrm{s}$.

The tangential stresses at the top and bottom layers of the blank section were integrated from the center of the blank to the flange end and were named SUMTOP and SUMBOT, respectively; their values are given in the figures. $\triangle \mathrm{TAN}$ is defined as $\triangle \mathrm{TAN}=\mathrm{SUMBOT}-\mathrm{SUMTOP}$, and their values are also given in the figures. With increasing temperature, SUMBOT changed from 12,443 to -421 , whereas SUMTOP changed from $-12,543$ to 288 . As a result, $\triangle \mathrm{TAN}$ decreased with increasing temperature. The importance of $\triangle \mathrm{TAN}$ in springback will be examined in the Discussion section. 


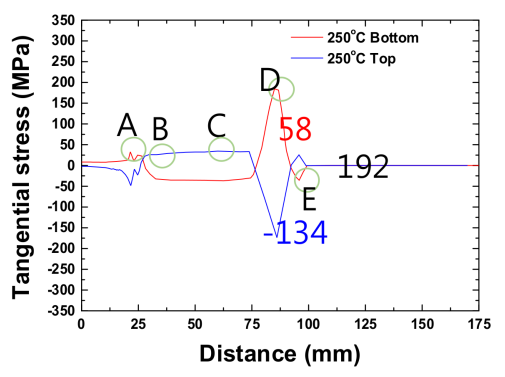

(a)

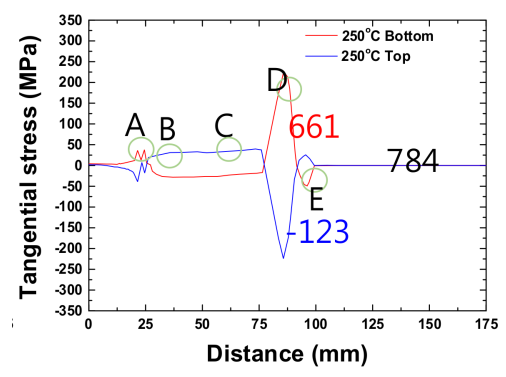

(b)

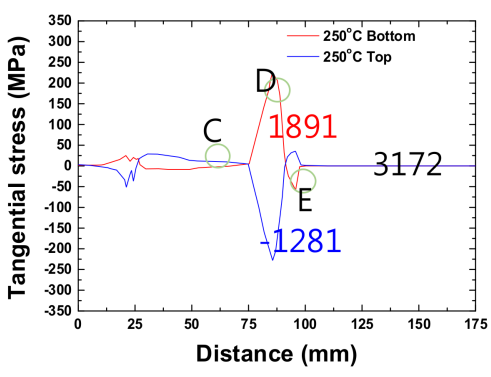

(c)

Figure 7. The tangential stress values at the top and bottom layers of the blank (under isothermal condition) for punch speeds of (a) 1 , (b) 5 and (c) $10 \mathrm{~mm} / \mathrm{s}$ at $250{ }^{\circ} \mathrm{C}$.

Figure 7a-c show the tangential stress values at the top and bottom layers of the blank for punch speeds of 1,5 and $10 \mathrm{~mm} / \mathrm{s}$ at $250{ }^{\circ} \mathrm{C}$ under isothermal condition. As the punch speed increased, SUMBOT and SUMTOP, whose signs were positive and negative, respectively, increased in magnitude because as the strain rate increased with increasing punch speed, the flow-stress level increased, and, thus, the bending moment of the blank increased. For this reason, $\triangle \mathrm{TAN}$ increased with increasing punch speed.

For the non-isothermal forming, the effects of temperature and strain rate on the value and distribution of tangential stresses are shown in Figures 8 and 9, respectively. As in the case of isothermal conditions, the tangential stress and $\triangle \mathrm{TAN}$ magnitudes decreased with increasing temperature (Figure 8a-d). However, there were two major differences when compared to the case of isothermal forming. First, the magnitudes of the tangential stresses and $\triangle T A N$ for the non-isothermal condition were larger than those for isothermal forming; the $\triangle \mathrm{TAN}$ decreased from 24,618 to 9583 under the non-isothermal condition as temperature increased from 150 to $300{ }^{\circ} \mathrm{C}$, whereas they decreased from 17,685 to -709 under the isothermal condition. As the temperatures around the punch and sidewalls were lower than the forming start temperatures under the non-isothermal condition, the larger magnitude of $\triangle \mathrm{TAN}$ was a result of the higher flow stresses, bending moments, and tangential stresses of the blank in comparison with those measured under isothermal forming. Second, the sign reversal of the tangential stress in the $\mathrm{BC}$ region did not occur up to $300^{\circ} \mathrm{C}$ under the non-isothermal condition, whereas it occurred at temperatures above $250{ }^{\circ} \mathrm{C}$ under the isothermal condition. This is also because the average temperature experienced by the material under the non-isothermal condition was lower than that experienced under the isothermal condition.

Under the isothermal forming described above (Figure $7 \mathrm{a}-\mathrm{c}$ ), the overall magnitudes of tangential stress and $\triangle \mathrm{TAN}$ increased as the punch speed increased from 1 to $10 \mathrm{~mm} / \mathrm{s}$. However, under the non-isothermal forming, an opposite trend was observed; the tangential stress and $\triangle T A N$ magnitudes decreased with increasing punch speed (Figure $9 \mathrm{a}-\mathrm{c}$ ). This is because, under the non-isothermal condition, as punch speed increased, the times for heat transfer from the material to the punch in the $\mathrm{BC}$ region were shorter, resulting in smaller decreases in material temperature during the forming process. When this temperature effect is more significant than the effect of strain rate itself, $\triangle T A N$ can decrease with increasing punch speed.

The relationship between $\Delta$ TAN and $\Delta \theta$ (from the FEM analysis results) is shown in Figure 10 for all cases, including the cases of isothermal and non-isothermal conditions. The results show that there was a good linear relationship between the two parameters (with a linear regression $R$-squared value of 0.94). From that observation, it can be inferred that quantitative prediction of springback is possible by observing only tangential stress distribution on the blank cross-section. 

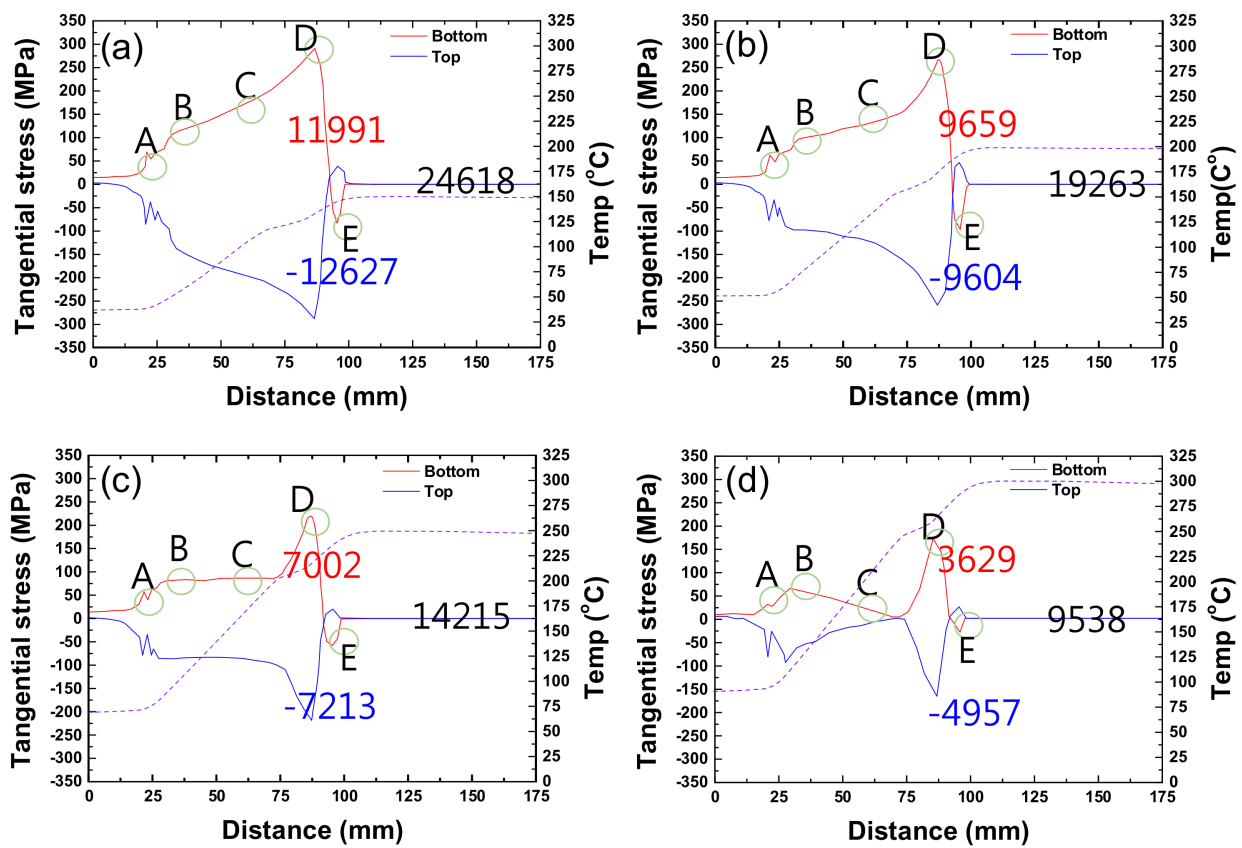

Figure 8. The tangential stress values in each distinct tooling region at the top and bottom layers of the blank (under non-isothermal condition) at (a) 150, (b) 200, (c) 250 and (d) $300{ }^{\circ} \mathrm{C}$. The dotted curves represent the temperature profile along the center of the cross-section of the sheet. For all cases, the punch speed was $1 \mathrm{~mm} / \mathrm{s}$.

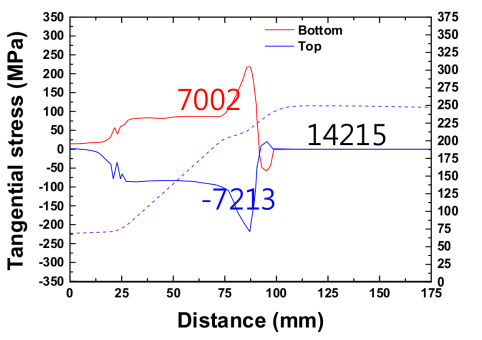

(a)

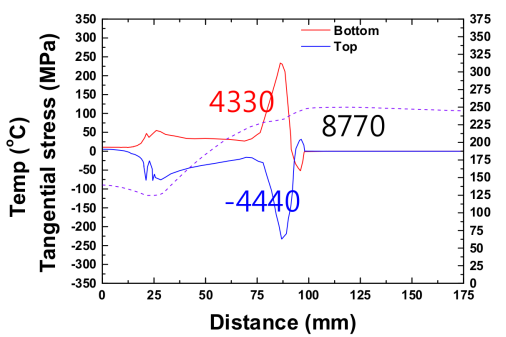

(b)

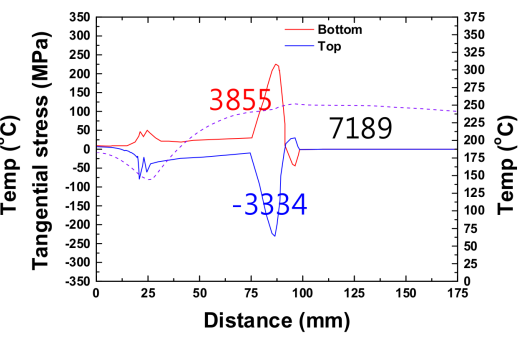

(c)

Figure 9. The tangential stress values at the top and bottom layers of the blank (under non-isothermal condition) for punch speeds of (a) 1 , (b) 5 and (c) $10 \mathrm{~mm} / \mathrm{s}$ at $250{ }^{\circ} \mathrm{C}$. The dotted curves represent the temperature profile along the center of the cross-section of the sheet.

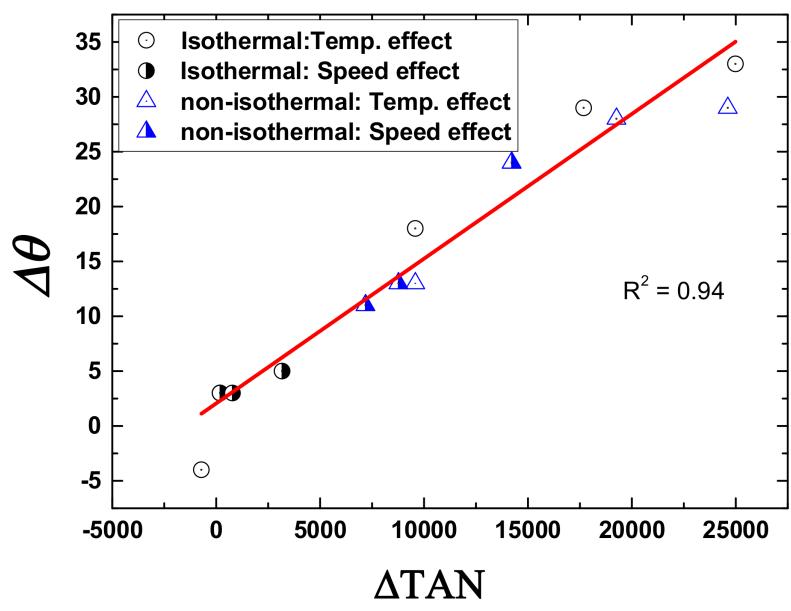

Figure 10. The relationship between $\Delta \theta$ and $\triangle \mathrm{TAN}$ for isothermal and non-isothermal conditions. 


\section{Discussion}

According to the plot in Figure 10, the magnitude of the springback of a $U$ draw-bended product is proportional to the difference in tangential stresses at the top and bottom layers of the sheet. In this section, we examine whether such results can be rationalized and present a springback prediction model that can utilize the tangential stress data obtained from the FEM forming analysis.

When effective stress and effective strain are used to depict the general state of stress in a material, Equation (6) changes to

$$
\bar{\sigma}=K \bar{\varepsilon}^{N} f\left(Z_{\text {eff }}\right)=K \bar{\varepsilon}^{N} f\left(\frac{\dot{\bar{\varepsilon}}}{D_{\text {eff }}}\right),
$$

where $\bar{\sigma}$ is the effective stress and $\bar{\varepsilon}$ is the effective strain.

When an arbitrary stress is distributed in the section of the sheet due to an externally applied load, it can be assumed that the stress distribution is decomposed into stresses due to pure bending and sheet stretching. In that case, pure bending causes a tensile (or compressive) stress that increases linearly from the neutral plane, and sheet stretching causes a uniform tensile stress in the sheet cross-section. If the sheet receives a compressive force in the in-plane direction, a uniform compressive stress may occur in the sheet cross-section. However, the magnitude of the compressive stress generated in the sheet cross-section is usually small, and if the in-plane compressive force is too large, the sheet will instead buckle. Thus, the presence of a uniform compressive stress is neglected in the following derivation.

The strain distributions on a sheet cross-section when a sheet undergoes different bending modes are schematically shown in Figure 11a,b. Figure 11a shows the strain distribution on a sheet cross-section due to pure bending, and Figure $11 \mathrm{~b}$ shows the strain distribution on a sheet cross-section when the tensile strain due to sheet stretching is added to the strain distribution caused by pure bending. Figure 11c shows the stress distribution on a sheet cross-section caused by the strain distribution of Figure 11b. Assuming that all regions of the cross-section are in a plastic deformation state, a nonlinear stress distribution appears.

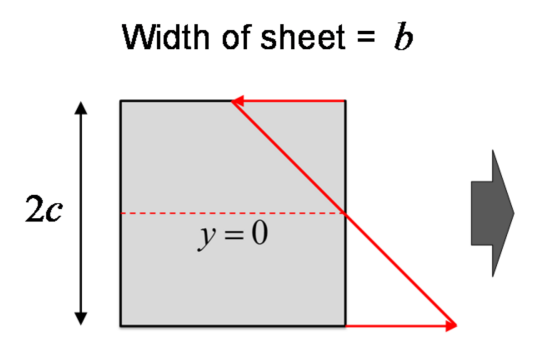

(a)

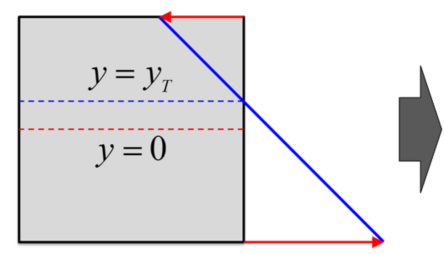

(b)

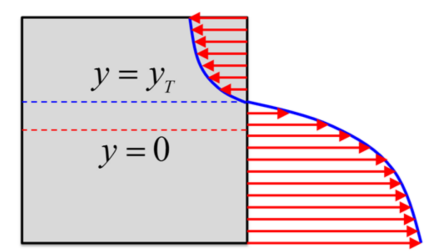

(c)

Figure 11. (a) the strain distribution on a sheet cross-section due to pure bending; (b) the strain distribution on the sheet cross-section upon the addition of a uniform tensile strain due to sheet stretching; and (c) the stress distribution on the sheet cross-section caused by the distribution of strain shown in (b).

According to the Euler-Bernoulli beam theory [25], the longitudinal strain of the beam can be calculated by

$$
\varepsilon_{x}=-\frac{y}{\bar{\rho}}+\bar{\varepsilon}_{T}=-\frac{y}{\bar{\rho}}+\frac{\bar{y}_{T}}{\bar{\rho}}=-\frac{\left(y-\bar{y}_{T}\right)}{\bar{\rho}},
$$

where $\bar{y}_{\mathrm{T}}$ is the distance from the sheet thickness center plane to the neutral plane in the sheet cross-section when the neutral plane moves due to the effect of sheet stretching, and $\bar{\rho}$ is the radius of curvature of the beam under bending. However, if the beam undergoes various plastic deformation paths, including tensile and compressive deformation, it is necessary to consider the deformation history. For that purpose, $\bar{y}_{\mathrm{T}}$ and $\bar{\rho}$ are defined as variables that reflect the deformation history. 
The stress distribution on the sheet cross-section can be obtained from Equations (9) and (10). If the sheet thickness is thin (i.e., a plane stress condition), and the variation of temperature and strain rate in the cross-section is not large, Equation (9) can be approximated as

$$
\sigma_{x}=K \varepsilon_{x}^{N} f\left(Z_{\mathrm{avg}}\right)
$$

where $Z_{\text {avg }}=\dot{\bar{\varepsilon}}_{\text {avg }} \exp \left(\frac{Q}{R T_{\text {avg }}}\right), K \approx K\left(T_{\text {avg }}\right)$, and $N \approx N\left(T_{\text {avg }}\right)$ for the average temperature $T_{\text {avg }}$ and the average strain rate $\dot{\bar{\varepsilon}}_{\text {avg }}$.

The bending moment due to the stress distribution in the cross-section can be calculated as

$$
\begin{aligned}
M_{B} & =\int_{\bar{y}_{\mathrm{T}}}^{c}\left(y-\bar{y}_{\mathrm{T}}\right) \sigma_{x} b \mathrm{~d} y+\int_{-c}^{\bar{y}_{\mathrm{T}}}\left(\bar{y}_{\mathrm{T}}-y\right) \sigma_{x} b \mathrm{~d} y \\
& =\int_{\bar{y}_{\mathrm{T}}}^{c} b\left(y-\bar{y}_{\mathrm{T}}\right)\left\{K\left(\frac{y-\bar{y}_{\mathrm{T}}}{\bar{\rho}}\right)^{N} f\left(Z_{\mathrm{avg}}\right)\right\} \mathrm{d} y+\int_{-c}^{\bar{y}_{\mathrm{T}}} b\left(\bar{y}_{\mathrm{T}}-y\right)\left\{K\left(\frac{\bar{y}_{\mathrm{T}}-y}{\bar{\rho}}\right)^{N} f\left(Z_{\mathrm{avg}}\right)\right\} \mathrm{d} y, \\
& =\frac{b K f\left(Z_{\mathrm{avg}}\right)}{\bar{\rho}^{N}}\left\{\frac{\left(c-\bar{y}_{\mathrm{T}}\right)^{N+2}+\left(c+\bar{y}_{\mathrm{T}}\right)^{N+2}}{N+2}\right\}
\end{aligned}
$$

where $b$ is the width of the sheet and $c$ is half the sheet thickness. When the external load is removed, the bending moment becomes zero due to elastic recovery. From a microscopic perspective of elastic recovery, an elastic stress is generated on the sheet cross-section that generates a bending moment of the same magnitude in the opposite direction. That elastic stress causes springback. The inverse of the radius of curvature is then given by the following equation

$$
\begin{aligned}
\frac{1}{\rho^{\mathrm{sb}}} & =\frac{M_{B}}{E I}=\frac{1}{E I} \times\left[\frac{b K f\left(Z_{\mathrm{avg}}\right)}{\bar{\rho}^{N}}\left\{\frac{\left(c-\bar{y}_{\mathrm{T}}\right)^{N+2}+\left(c+\bar{y}_{\mathrm{T}}\right)^{N+2}}{N+2}\right\}\right], \\
& =\frac{1.5 K}{E \bar{\rho}^{N}(N+2)} \times \frac{\left[\left(c-\bar{y}_{\mathrm{T}}\right)^{N+2}+\left(c+\bar{y}_{\mathrm{T}}\right)^{N+2}\right]}{c^{3}} f\left(Z_{\mathrm{avg}}\right)
\end{aligned}
$$

where the area moment of inertia $I=2 b c^{3} / 3$ was used.

The angle change due to the springback can then be obtained as follows:

$$
\Delta \theta^{\mathrm{sb}}=\frac{\Delta L}{\rho^{\mathrm{sb}}}=\Delta L\left\{\frac{1.5 K}{E \bar{\rho}^{N}(N+2)} \times \frac{\left[\left(c-\bar{y}_{\mathrm{T}}\right)^{N+2}+\left(c+\bar{y}_{\mathrm{T}}\right)^{N+2}\right]}{c^{3}} f\left(Z_{\mathrm{avg}}\right)\right\},
$$

where $\Delta L$ denotes the length of the sheet element where the angle change $\Delta \theta^{\mathrm{sb}}$ occurred.

The tangential stresses occurring at the bottom Equation (15) and top layers of the sheet Equation (16) can be expressed as follows, respectively:

$$
\begin{gathered}
\sigma_{\mathrm{a}}=K\left(\frac{c+\bar{y}_{\mathrm{T}}}{\bar{\rho}}\right)^{N} f\left(Z_{\mathrm{avg}}\right), \\
\sigma_{\mathrm{b}}=-K\left(\frac{c-\bar{y}_{\mathrm{T}}}{\bar{\rho}}\right)^{N} f\left(Z_{\mathrm{avg}}\right) .
\end{gathered}
$$

In the case of $\bar{y}_{\mathrm{T}}=0$ in the above equations, the stresses in the sheet cross-section assume a symmetrical distribution that changes from tension to compression with respect to the neutral plane. In the case of $\bar{y}_{\mathrm{T}}=c$, the stress throughout the sheet cross-section is in a tensile state. From Equations (15) and (16), the parameters $\bar{y}_{\mathrm{T}}$ and $\bar{\rho}=\bar{\rho}(x)$ can be expressed as 


$$
\begin{aligned}
& \bar{y}_{\mathrm{T}}=c\left[\frac{\left(-\frac{\sigma_{\mathrm{a}}}{\sigma_{\mathrm{b}}}\right)^{\frac{1}{N}}-1}{\left(-\frac{\sigma_{\mathrm{a}}}{\sigma_{\mathrm{b}}}\right)^{\frac{1}{N}}+1}\right], \\
& \bar{\rho}=\left(c+\bar{y}_{\mathrm{T}}\right) K^{\frac{1}{N}}\left\{\frac{f\left(\mathrm{Z}_{\text {avg }}\right)}{\sigma_{\mathrm{a}}}\right\}^{\frac{1}{N}} .
\end{aligned}
$$

If $\sigma_{\mathrm{a}}$ is tensile and $\sigma_{\mathrm{b}}$ is compressive, the difference in the tangential stresses at the top and bottom layers of the sheet, $\sigma_{a-b}$, is then

$$
\sigma_{\mathrm{a}-\mathrm{b}}=\sigma_{\mathrm{a}}-\sigma_{\mathrm{b}}=\left[\left(\frac{c+\bar{y}_{\mathrm{T}}}{\bar{\rho}}\right)^{N}+\left(\frac{c-\bar{y}_{\mathrm{T}}}{\bar{\rho}}\right)^{N}\right] K f\left(Z_{\mathrm{avg}}\right) .
$$

Equation (14) can be expressed in terms of $\sigma_{\mathrm{a}-\mathrm{b}}$ as

$$
\begin{aligned}
\Delta \theta^{\mathrm{sb}} & =\Delta L \frac{1.5}{\overline{E(N+2)}} \times\left[\frac{\left(c-\bar{y}_{\mathrm{T}}\right)^{N+2}+\left(c+\bar{y}_{\mathrm{T}}\right)^{N+2}}{\bar{\rho}^{N} c^{3}}\right] K f\left(Z_{\mathrm{avg}}\right) \\
& \approx \Delta L \frac{1.5 c^{-1}}{E(N+2)} \times\left[\frac{\left(c-\bar{y}_{\mathrm{T}}\right)^{N} c^{2}+\left(c+\bar{y}_{\mathrm{T}}\right)^{N} c^{2}}{\bar{\rho}^{N} c^{2}}\right] K f\left(Z_{\mathrm{avg}}\right) . \\
& =\Delta L \frac{1.5 c^{-1}}{E(N+2)} \sigma_{\mathrm{a}-\mathrm{b}} .
\end{aligned}
$$

The total cumulative value of the angle change can be determined by converting the above equation found for a sheet element of length $\Delta L$ into an equation for an element of infinitesimal length $\mathrm{d} x$ and integrating it over the entire length:

$$
\begin{gathered}
\int_{0}^{\Delta \theta^{\mathrm{sb}}} \mathrm{d} \theta^{\mathrm{sb}}=\int_{0}^{L} \frac{1.5 c^{-1}}{E(N+2)} \sigma_{\mathrm{a}-\mathrm{b}} \mathrm{d} x \\
\Delta \theta^{\mathrm{sb}}=\int_{0}^{L} \frac{1.5 c^{-1}}{E(N+2)} \sigma_{\mathrm{a}-\mathrm{b}} \mathrm{d} x=\frac{1.5 c^{-1}}{E(N+2)} \Delta \mathrm{TAN}, \\
\Delta \mathrm{TAN}=\int_{0}^{L} \sigma_{\mathrm{a}-\mathrm{b}} \mathrm{d} x=\int_{0}^{L}\left[\left(\frac{c+\bar{y}_{\mathrm{T}}}{\bar{\rho}}\right)^{N}+\left(\frac{c-\bar{y}_{\mathrm{T}}}{\bar{\rho}}\right)^{N}\right] K f\left(Z_{\mathrm{avg}}\right) \mathrm{d} x .
\end{gathered}
$$

If $\sigma_{\mathrm{a}}$ is compressive and $\sigma_{\mathrm{b}}$ is tensile, however, $\sigma_{\mathrm{a}-\mathrm{b}}$ and $\mathrm{d} \theta^{\mathrm{sb}}$ will be equal in magnitude but opposite in sign compared to the case where $\sigma_{a}$ is tensile and $\sigma_{b}$ is compressive. Therefore, $\sigma_{a-b}$ in Equation (18) should be expressed in a more general form as

$$
\sigma_{\mathrm{a}-\mathrm{b}}=\left[\operatorname{sign}\left(\sigma_{\mathrm{a}}\right) \times\left(\frac{c+\bar{y}_{\mathrm{T}}}{\bar{\rho}}\right)^{N}-\operatorname{sign}\left(\sigma_{\mathrm{b}}\right) \times\left(\frac{c-\bar{y}_{\mathrm{T}}}{\bar{\rho}}\right)^{N}\right] K f\left(Z_{\mathrm{avg}}\right) .
$$

The followings are inferred from Equation (21). First, $\Delta \theta^{\text {sb }}$ is linearly proportional to $\Delta$ TAN, which agrees with the trend shown in Figure 10. Second, according to Equations (3), (8) and (22), $\Delta$ TAN increases as strain rate increases and temperature decreases. Thus, $\Delta \theta^{\text {sb }}$ increases as strain rate increases and temperature decreases. Third, $\Delta \theta^{\mathrm{sb}}$ increases as $E$ decreases, which is in good agreement with the general observation that smaller $E$ yields greater springback [26]. Fourth, $\Delta \theta^{\text {sb }}$ is inversely proportional to $c$ because $\triangle$ TAN is proportional to the $N$ power of $c$, whereas the slope of the curve of $\Delta \theta^{\mathrm{sb}}$ vs. $\Delta$ TAN is proportional to the -1 power of $c$, consequently leading to $\Delta \theta^{\mathrm{sb}} \alpha$ $(N-1)$ power of $c$. Because $N$ is usually less than $1, \Delta \theta^{\text {sb }}$ is inversely proportional to $c$. This prediction also matches the general tendency that the amount of springback increases with decreasing sheet thickness. Ho et al. [27] analyzed the springback behavior of creep forming of aluminum sheets using a finite element method and showed that springback decreases with increasing workpiece thickness. Liu et al. [28] analyzed the unloading springback of sheet metal foils after a micro-bending process 
using a developed finite element model and showed that springback angle generally increases with decreasing sheet thickness. Fifth, $\Delta \theta^{\mathrm{sb}}$ increases as $N$ increases and $\bar{\rho}$ decreases.

According to Equation (21), the slope of the curve of $\Delta \theta^{\text {sb }}$ vs. $\Delta \mathrm{TAN}, S\left(=\frac{1.5 c^{-1}}{E(N+2)}\right)$ is a function of $E, N$, and $c$. Under the present experimental conditions, as temperature increases, $E$ decreases from 73.1 to $60.3 \mathrm{GPa}$ (Table 1) and $N$ decreases from 0.37 to 0 . With $c=0.55 \mathrm{~mm}$, the average $E$ value of $66 \mathrm{GPa}$ and the $N$ value in range between 0 and $0.37, S$ was calculated to be in range between $1.74 \times 10^{-5}$ and $2.07 \times 10^{-5} / \mathrm{MPa} \cdot \mathrm{mm}$. The slope measured from the plot in Figure 10 is $2.01 \times 10^{-5} / \mathrm{MPa} \cdot \mathrm{mm}$, indicating that the slope $(S)$ of the derived formula is very similar to the slope of the plot obtained from the FEM analysis results. This result verifies that the cumulative springback angle can be estimated directly from the information on the tangential stress difference.

When deriving the explicit forms of the above equations, several simplifying assumptions were made. Nevertheless, Equation (21) supports the observed trend that $\Delta$ TAN is proportional to $\Delta \theta^{\mathrm{sb}}$ and predict the dependencies of several parameters on $\Delta \theta^{\mathrm{sb}}$ correctly. Therefore, application of Equation (21) can potentially be extended beyond the material type and the case of U-draw bending, having found its usefulness in predicting the amounts of springback in warm sheet metal forming processes.

\section{Conclusions}

1. U-draw bending tests were conducted over a temperature range between 150 and $300{ }^{\circ} \mathrm{C}$ under isothermal and non-isothermal conditions.

2. Under both isothermal and non-isothermal conditions, the amount of springback $(\Delta \theta)$ decreased as temperature increased and punch speed decreased. Larger amounts of springback occurred under the non-isothermal condition.

3. FEM simulations were performed under the experimental conditions, and it was found that the calculated and experimentally measured springbacks agreed.

4. There was a good linear relationship between the difference in tangential stresses at the top and bottom layers of the sheet section $(\Delta T A N)$ and $\Delta \theta$ for all cases, including those for different temperatures and punch speeds under isothermal and non-isothermal conditions. This observation suggests the possibility of making quantitative predictions of springback by considering tangential stress distributions on blank cross-sections.

5. A functional model that can quantitively explain the correlation between $\Delta \theta$ and $\Delta$ TAN was derived based on an Euler beam and a nonlinear flow stress model with temperature and strain rate dependencies. According to the model, springback decreases as strain rate decreases, temperature increases, elastic modulus increases, sheet thickness increases, strain hardening exponent decreases and the radius of curvature of the beam under bending increases.

Acknowledgments: This research was supported by the Mid-Career Researcher Program through the National Research Foundation of Korea (2016) funded by the Ministry of Education, Science and Technology (2016R1A2B4015481) and the basic research support program funded by the Ministry of Education (NRF-2017 R1D1A1B03029350).

Author Contributions: Woo-Jin Kim performed the forming experiments and finite element analysis, and proposed the linear correlation between $\Delta \theta$ and $\Delta$ TAN; Heung-Kyu Kim derived the springback prediction model and evaluated the validity of the model.

Conflicts of Interest: The authors declare no conflict of interest.

\section{References}

1. Cole, G.S.; Sherman, A.M. Light weight materials for automotive applications. Mater. Charact. 1995, 35, 3-9. [CrossRef]

2. Ismail, A.; Mohamed, M.S. Review on sheet metal forming process of aluminium alloys. In Proceedings of the 17th International Conference on Applied Mechanics and Mechanical Engineering, Cairo, Egypt, 19-21 April 2016; pp. 129-141. 
3. Naka, T.; Torikai, G.; Hino, R.; Yoshida, F. The effects of temperature and forming speed on the forming limit diagram for type 5083 aluminum-magnesium alloy sheet. J. Mater. Process. Technol. 2001, 113, 648-653. [CrossRef]

4. Kim, W.J.; Kim, W.Y.; Kim, H.K. Hot-air forming of Al-Mg-Cr alloy and prediction of failure based on Zener-Holloman parameter. Met. Mater. Int. 2010, 16, 895-903. [CrossRef]

5. Rashid, M.S.; Kim, C.; Ryntz, E.F.; Saunders, F.I.; Verma, R.; Kim, S. Quick Plastic Forming of Aluminum Alloy Sheet Metal. U.S. Patent 6,253,588, 3 July 2001.

6. Laurent, H.; Coër, J.; Grèze, R.; Manach, P.Y.; Andrade-Campos, A.; Oliveira, M.C.; Menezes, L.F. Mechanical behaviour and springback study of an aluminium alloy in warm forming conditions. ISRN Mech. Eng. 2011, 2011, 381615. [CrossRef]

7. Kim, H.S.; Koc, M.; Ni, J. Determination of proper temperature distribution for warm forming of aluminum sheet materials. ASME J. Manuf. Sci. Eng. 2006, 128, 622-633. [CrossRef]

8. Takuda, H.; Mori, K.; Masuda, I.; Abe, Y.; Matsuo, M. Finite element simulation of warm deep drawing of aluminium alloy sheet when accounting for heat conduction. J. Mater. Process. Technol. 2002, 120, 412-418. [CrossRef]

9. Li, D.; Ghosh, A. Tensile deformation behavior of aluminum alloys at warm forming temperatures. Mater. Sci. Eng. A 2003, 352, 279-286. [CrossRef]

10. Abedrabbo, N.; Pourboghrat, F.; Carsley, J. Forming of aluminum alloys at elevated temperatures-Part 1: Material characterization. Int. J. Plast. 2006, 22, 314-341. [CrossRef]

11. Toros, S.; Ozturk, F.; Kacar, I. Review of warm forming of aluminum-magnesium alloys. J. Mater. Process. Technol. 2008, 207, 1-12. [CrossRef]

12. Moon, Y.H.; Kang, Y.K.; Park, J.W.; Gong, S.R. Tool temperature control to increase the deep drawability of aluminum 1050 sheet. Int. J. Mach. Tool. Manuf. 2001, 41, 1283-1294. [CrossRef]

13. Keum, Y.T.; Han, B.Y. Springback of FCC sheet in warm forming. Ceram. Process. Res. 2002, 3, $159-165$.

14. Yanagimoto, J.; Oyamada, K. Springback-free isothermal forming of high-strength steel sheets and aluminum alloy sheets under warm and hot forming conditions. ISIJ Int. 2006, 46, 1324-1328. [CrossRef]

15. Kim, H.S.; Koç, M. Numerical investigations on springback characteristics of aluminum sheet metal alloys in warm forming conditions. J. Mater. Process. Technol. 2008, 204, 370-383. [CrossRef]

16. Makinouchi, A.; Teodosiu, C.; Nakagawa, T. Advance in FEM simulation and its related technologies in sheet metal forming. CIRP Ann. 1998, 47, 641-649. [CrossRef]

17. Narasimhan, N.; Lovell, M. Predicting springback in sheet metal forming: An explicit to implicit sequential solution procedure. Finite Elem. Anal. Des. 1999, 33, 29-42. [CrossRef]

18. Chang, D.H.; Kim, W.J. Warm temperature behavior and processing maps of 5182 and 7075 aluminum alloy sheets with fine grains. Met. Mater. Int. 2018. [CrossRef]

19. Naka, T.; Yoshida, F. Deep drawability of type 5083 aluminium-magnesium alloy sheet under various conditions of temperature and forming speed. J. Mater. Process. Technol. 1999, 89, 19-23. [CrossRef]

20. Benck, R.F.; Filbey, G.L., Jr. Elastic Constants of Aluminum Alloys, 2024-T3510, 5083-H131 and $7039-T 64$ as Measured by a Sonic Technique; BRL-MR-2649; USA Ballistic Research Laboratories, Aberdeen Proving Ground: Harford, MD, USA, 1976.

21. Hosford, W.F.; Caddell, R.M. Metal Forming, Mechanics and Metallurgy, 3rd ed.; Cambridge University Press: New York, NY, USA, 1993; ISBN 9780521881210.

22. Sherby, O.D.; Burke, P.M. Mechanical behavior of crystalline solids at elevated temperature. Prog. Mater. Sci. 1968, 13, 323-390. [CrossRef]

23. Frost, H.J.; Ashby, M.F. Deformation Mechanism Maps: The Plasticity and Creep of Metals and Ceramics, 1st ed.; Pergamon Press: New York, NY, USA, 1982; ISBN 9780080293387.

24. Kim, H.K.; Kim, W.J. Failure prediction of magnesium alloy sheets deforming at warm temperatures using the Zener-Holloman parameter. Mech. Mater. 2010, 42, 293-303. [CrossRef]

25. Timoshenko, S. History of Strength of Materials; McGraw-Hill: New York, NY, USA, 1953.

26. Yu, H.Y. Variation of elastic modulus during plastic deformation and its influence on springback. Mater. Des. 2009, 30, 846-850. [CrossRef] 
27. Ho, K.C.; Lin, J.; Dean, T.A. Modelling of springback in creep forming thick aluminum sheets. Int. J. Plast. 2004, 20, 733-751. [CrossRef]

28. Liu, J.G.; Fu, M.W.; Lu, J.; Chan, W.L. Influence of size effect on the springback of sheet metal foils in micro-bending. Comput. Mater. Sci. 2011, 50, 2604-2614. [CrossRef] 